\title{
The Norwegian Prescription Database (NorPD) as a data source for diabetes research
}

\author{
Christian Berg and Hanne Strøm \\ Department of Pharmacoepidemiology, Norwegian Institute of Public Health, Norway
}

\begin{abstract}
All diagnosed patients with type 1 diabetes and a large majority of patients with type 2 diabetes in most Western countries are treated with blood glucose-lowering drugs. Data from nationwide prescription drug databases can therefore be used to estimate prevalence and incidence of drug-treated diabetes and trends over time, although there are limitations of such data.
\end{abstract}

\section{ABOUT THE NORPD}

Every month since 2004, the Norwegian Institute of Public Health has received automatically generated data on prescriptions from all Norwegian pharmacies (1). NorPD contains information about all drugs prescribed (reimbursed or not) and dispensed at pharmacies to individual patients living outside institutions, i.e. ambulatory care. For patients in nursing homes and hospitals, the figures for drug use are included in the register at institution or department level, i.e. on an aggregated level.

The NorPD has a website for easy access to prescription statistics in Norway (2). All patients with at least one prescription dispensed during a year are included in the database. Reports on the number of users of a particular drug or drug group can be retrieved. Detailed information can be obtained by performing searches using the Anatomical Therapeutic Chemical (ATC) code, substance name or brand name. The database is annually updated with data from the preceding year. Data from the NorPD are also published in an annual report (3). For research and e.g. surveillance purposes which are in accordance with the aims of the NorPD, further information is available upon request (4).

\section{TREATMENT WITH BLOOD GLUCOSE- LOWERING DRUGS AS A PROXY FOR DIABETES}

Blood glucose-lowering drugs are classified in the ATC group A10 Drugs used in diabetes. The group is subdivided into Insulins and analogues (A10A) and Other blood glucose-lowering drugs (non-insulins, A10B) (5).

While many approaches of estimating the total number of individuals diagnosed with diabetes in a population are likely to have significant sources of error, data from nationwide prescription drug databases can overcome problems of for example biased participation and limited sample sizes.

The use of dispensed drugs as proxy for diabetes will obviously result in an underestimation of the total number of diabetes patients in the population since a significant proportion of individuals with Type 2 diabetes is treated with lifestyle measures alone. Furthermore, the proportion of individuals with undiagnosed diabetes is considerable.

Classification of type 1 versus type 2 diabetes is challenging in a prescription database. In children, insulin use essentially indicates a diagnosis of type 1 diabetes. In the older age groups, both patients with type 1 and type 2 diabetes may be treated with insulins.

\section{CALCULATING PREVALENCE AND INCIDENCE}

A simple NorPD search reveals that in 2012 approximately 161,000 individuals ( $3.2 \%$ of the population) had at least one prescription of a drug in ATC group A10 dispensed; the prevalence according to age groups and gender are shown in Figure 1. For insulins the number was $56,300(1.1 \%)$ and for non-insulins $124,900(2.5 \%)(3)$. It is important to be aware of the fact that patients receiving both insulins $(\mathrm{A} 10 \mathrm{~A})$ and another blood glucose-lowering drug (A10B), will only be counted once on an aggregated level (A10). Thus about 20,200 individuals had in 2012 received drugs from both subgroups.

While patients treated with non-insulins are most likely to suffer from Type 2 diabetes, individuals treated with insulins could suffer from either type 1 or type 2 diabetes. For type 2 diabetes, drug treatment may be discontinued or intensified e.g. by adding insulin. It is therefore important to follow treatment of individuals over years.

Estimating the number of patients with type 1 or type 2 diabetes treated with blood glucose-lowering drugs requires a more sophisticated approach. In NorPD, different lengths of drug free period may be applied. For example, individuals who had at least one prescription of insulin dispensed during an observation year, but had no other blood glucose-lowering drugs in the two years period prior to the first prescription could be counted as prevalent users of insulin only, and thus possible type 1 diabetes patients.

There are also several methods for calculating the proportion of new users (incident users) being treated with insulins and analogues and/or other blood glucose-lowering drugs. The different approaches may, with limitations, indicate the number of new individuals with type 1 versus type 2 diabetes treated with drugs.

\section{RESEARCH INCLUDING DATA FROM THE NORPD}

Based on data from the NorPD from January 2004 to June 2005, the prevalence and incidence of drugtreated diabetes in Norway have been studied (6). It was concluded that the NorPD provides a good estimate of the number of patients diagnosed with diabetes who receive blood glucose-lowering drugs outside hospitals and nursing homes. 


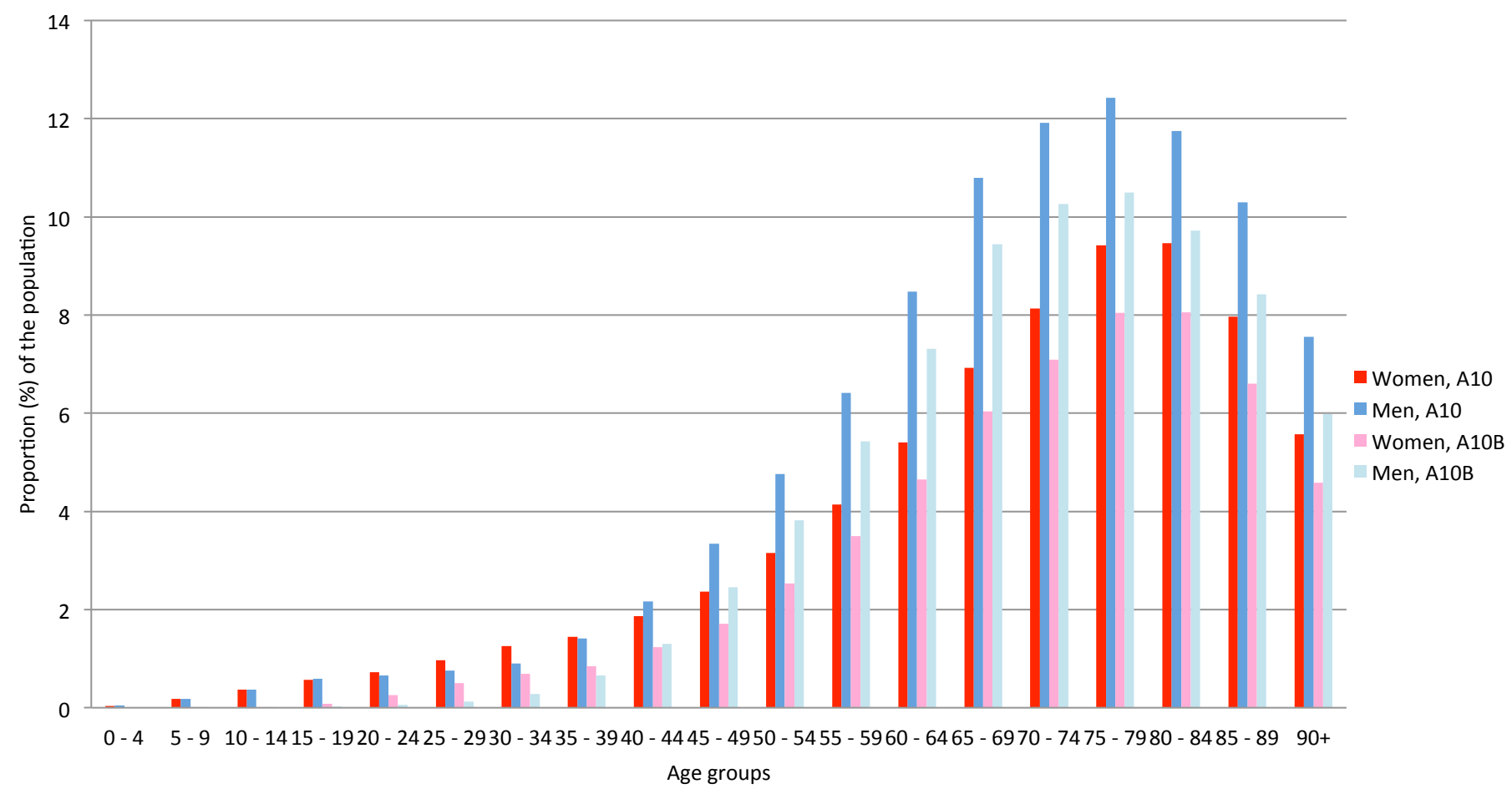

Figure 1. Proportion of the population (prevalence) with at least one blood glucose-lowering drug (A10) or non-insulins (A10B) dispensed in 2012 according to age groups and gender. Source: NorPD.

A European study including data from NorPD compared the prevalence of diabetes in children across seven European countries, using prescription of blood glucose-lowering drugs as a proxy for diabetes. A varying frequency of type 1 diabetes in children and adolescents across Europe was shown. It was demonstrated that it is possible to obtain similar information from different clinical databases within Europe, which would allow continuous monitoring of type 1 diabetes in children (7).

Data from NorPD has been linked to the Norwegian Childhood Diabetes Mellitus Registry to study the completeness of the information in the Registry. Using insulin prescriptions in the NorPD as reference, the detection rate of type 1 diabetes in the Norwegian Childhood Diabetes Mellitus Registry was estimated to be $91 \%(8)$.

\section{ON-GOING RESEARCH}

A working group with representatives from clinical practice and the Norwegian Institute of Public Health, supported by the Norwegian Diabetes Association, is analysing data from NorPD to describe time-trends in prevalence and incidence of diabetes treated with blood glucose-lowering drugs. This will contribute to an updated estimate of the total number of patients with diabetes in Norway.

\section{REFERENCES}

1. Strøm H. Reseptbasert legemiddelregister: et viktig verktøy for å oppnå detaljert legemiddelstatistikk. Norsk Epidemiologi 2004; 14 (1): 53-55.

2. The Norwegian Prescription Database. www.norpd.no, accessed April 2013.

3. The Norwegian Prescription Database 2008-2012. http://www.fhi.no/dokumenter/a6cce59ca6.pdf, accessed May 2013.

4. Norwegian Institute of Public Health, http://www.fhi.no/helseregistre/reseptregisteret, accessed April 2013.

5. WHO Collaborating Centre for Drug Statistics Methodology. ATC classification index with DDDs 2013. Oslo, 2012.

6. Strøm H, Engeland A, Eriksen E, Sakshaug S, Rønning M. [How many and who are receiving medication for diabetes mellitus? Article in Norwegian] Tidsskr Nor Lageforen 2006; 126: 768-70.

7. Neubert A, Hsia Y, de Jong-van den Berg LT, Janhsen K, Glaeske G, Furu K, et al. Comparison of antidiabetic drug prescribing in children and adolescents in seven European countries. Br J Clin Pharmacol 2011; 72: 969-977.

8. Skrivarhaug T, Stene LC, Strøm H, Drivvoll AK, Njølstad PR, Joner G, the Norwegian Childhood Diabetes Study Group: Increasing incidence of childhood onset Type 1 diabetes in Norway (Abstract). Diabetologia 2010; 53 (Suppl 1): S142. 